\title{
Pengaruh Pemberian Antibiotik Terhadap Populasi dan Produksi Toksin Clostridium difficile pada Pasien Demam Tifoid dan Pneumonia serta Hubungannya dengan Gejala Diare
}

\author{
Dwi Prasetyo
}

Clostridium difficile merupakan flora normal dalam saluran pencernaan manusia, tetapi dalam keadaan tertentu dapat menimbulkan penyakit, yaitu menjadi patogen bila ada kesempatan untuk bermultiplikasi dan membentuk toksin. Misalnya pemberian obat anti jasad renik dapat menekan sementara unsur-unsur flora usus yang peka terhadap obat tersebut. Sebaliknya kuman yang resisten tetap hidup, bahkan akan berkembang terus sehingga terjadi pertumbuhan yang berlebih. Di Indonesia Clostridium difficile belum begitu dikenal sebagai penyebab kolitis akibat pemakaian antibiotik. Kemungkinan karena kurangnya kewaspadaan dalam klinik, tidak tersedianya fasilitas laboratorium yang khusus untuk biakan anaerob atau kegagalan dalam melakukan biakan anaerob.

Tujuan penelitian untuk mengetahui jumlah kultur Clostridium difficile yang positif pada pemeriksaan hari pertama (maksimum mendapat 3 hari pengobatan antibiotik), peningkatan populasi Clostridium difficile dalam tinja pasien demam tifoid dan pneumonia yang mendapatkan pengobatan antibiotik 8 hari, adanya toksin Clostridium difficile dalam tinja anak penderita demam tifoid dan pneumonia yang mendapat pengobatan antibiotik 8 hari dan mengevaluasi hubungannya dengan gejala diare. Penelitian ini dilakukan terhadap 38 pasien demam tifoid dan 12 pasien pneumonia yang mendapat antibiotik minimal 8 hari dan dirawat di Sub Bagian Infeksi dan Pulmonologi Bagian Ilmu Kesehatan Anak FK-Unpad/Rumah Sakit Umum Pusat Dr. Hasan Sadikin, Bandung. Sebagai kontrol dilakukan pemeriksaan tinja pada 20 anak sehat. Pemeriksaan bakteriologik dilakukan di Laboratorium Mikrobiologi, Fakultas Kedokteran Universitas Padjadjaran, Bandung.

Dari 50 pasien yang diteliti didapatkan 24 (48,0\%) laki-laki dan 26 (52,0\%) perempuan. Kelompok umur 1-4, 5-9, dan $\geq 10$ tahun berturut-turut didapatkan 26 $(52,0 \%), 13(26,0 \%)$ dan $11(22,0 \%)$. Antibiotik kloramfenikol diberikan pada 38 (76,0\%) anak, sedangkan ampisilin pada $12(24,0 \%)$ anak. Hasil kultur Clostridium difficile pertama positif sebanyak $30(60,0 \%)$ dan negatif $20(40,0 \%)$ pasien. Ternyata pada kelompok anak sehat ditemukan 8 anak dengan kultur Clostridium difficile positif $(40,0 \%)$ dan 12 anak dengan kultur negatif (60,0\%). Dari hasil perhitungan statistik tidak didapatkan perbedaan yang bermakna jumlah rata-rata koloni Clostridium difficile per gram tinja pada kelompok anak sehat dan pasien infeksi yang diambil pada hari pertama perawatan yang sebelumnya telah mendapat maksimum 3 hari antibiotik. Didapatkan peningkatan jumlah koloni Clostridium difficile secara bermakna pada anak pasien demam tifoid dan pneumonia setelah diberi antibiotik 8 hari. Walaupun toksin Clostridium difficile terdeteksi pada $24,0 \%$ pasien, tetapi yang disertai gejala diare hanya pada 2 penderita. Juga didapatkan perbedaan bermakna rata-rata jumlah koloni Clostridium difficile per gram tinja antara pasien dengan toksin positif dan negatif. Pada semua anak yang didapatkan toksin Clostridium difficile ternyata mempunyai jumlah koloni Clostridium difficile melebihi $10^{3}$ koloni per gram tinja.

Kata kunci: Clostridium difficile, populasi, toksin, antibiotik, diare 


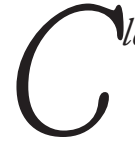
lostridium difficile merupakan kuman flora normal dalam saluran pencernaan manusia, juga dapat ditemukan dalam tanah, rumput kering, pasir, kotoran hewan seperti sapi, kuda, keledai, anjing, kucing dan hewan pengerat. 1 Walaupun demikian dalam keadaan-keadaan tertentu kuman flora normal ini dapat menjadi patogen bila ada kesempatan untuk bermultiplikasi, membentuk toksin atau mengadakan invasi ke jaringan lain, misalnya akibat pemberian antibiotik dan sitostatik. ${ }^{2,3}$ Obat-obatan anti jasad renik (antibiotik) yang diberikan secara oral atau parenteral pada manusia dapat menekan sementara unsur-unsur flora usus yang peka terhadap obat tersebut. Namun sebaliknya kuman yang resisten tetap hidup, akan tetap berkembang sehingga terjadi pertumbuhan yang berlebih. $^{2}$

Di Indonesia, jumlah kasus penyakit infeksi masih tinggi, sehingga penggunaan antibiotik juga cukup tinggi. ${ }^{4}$ Hal tersebut juga tampak di Rumah Sakit Umum Pusat Dr. Hasan Sadikin, Bandung, khususnya di Bagian Anak. Beberapa jenis antibiotik yang sering digunakan di bangsal anak antara lain ampisilin, amoksisilin, kloramfenikol, kotrimoxazol, golongan sefalosporin dan aminoglikosida.

Untuk pengobatan demam tifoid dan pneumonia, lamanya pemberian antibiotik antara 10-14 hari dan diberikan secara oral maupun parenteral.5,6 Walaupun pemakaian antibiotik telah berhasil menurunkan angka kesakitan dan kematian pelbagai penyakit infeksi, namun pemberian jangka panjang dan berspektrum luas dapat menimbulkan berbagai masalah. Masalah tersebut dapat merugikan pasien, seperti tumbuhnya bakteri patogen yang resisten terhadap antibiotik dan terganggunya keseimbangan flora normal. ${ }^{7}$

Di Indonesia Clostridium difficille belum begitu dikenal sebagai penyebab kolitis akibat pemakaian antibiotik mungkin disebabkan kurangnya kewaspadaan dalam klinik, tidak tersedianya fasilitas laboratorium yang khusus untuk biakan anaerob atau kegagalan dalam melakukan teknik biakan anaerob.

\footnotetext{
Alamat Korespondensi:

Dr. Dwi Prasetyo, Sp.A

Bagian/SMF Ilmu Kesehatan Anak FKUP/RSUP dr. Hasan Sadikin Jl.

Pasteur No. 38

Telp./Fax. 2034426-203595 Bandung 40161
}

Salah satu gejala kolitis paling sering adalah diare, diagnosis pasti dengan pemeriksaan patologi anatomi dengan endoskopi. Pada penelitian ini kedua pemeriksaan tersebut tidak dilakukan secara rutin, karena bersifat invasif dan mahal, sehingga yang diamati adalah gejala diare.

\section{Bahan dan Cara}

Penelitian ini merupakan studi kohort prospektif. Penderita yang ikut dalam penelitian ini adalah pasien demam tifoid dan pneumonia yang dirawat di Sub Bagian Infeksi dan Pulmonologi Bagian Ilmu Kesehatan Anak RSUP Dr. Hasan Sadikin Bandung. Pasien belum mendapat antibiotik atau maksimum mendapat 3 hari pengobatan sebelum dirawat (berdasarkan anamnesis). Menurut Feigin dan Finta (1992) gejala klinis kolitis yang timbul paling cepat 4 hari setelah pengobatan antibiotik dan masih dapat timbul setelah 21 hari antibiotik dihentikan. ${ }^{8}$ Pemilihan kasus dilakukan secara urutan pasien datang ke Rumah Sakit (consecutive admission) dan memenuhi kriteria penelitian.

Sebagai kontrol adalah anak berumur lebih dari 1 tahun yang beredar di poliklinik Tumbuh Kembang dan keluarga perawat yang bertugas di Bagian Ilmu Kesehatan Anak RSUP Dr. Hasan Sadikin dengan pembagian kelompok umur sesuai dengan subjek penelitian.

Kriteria Inklusi adalah anak berumur lebih dari 1 tahun, belum mendapat antibiotik atau yang paling lama mendapat antibiotik selama 3 hari sebelum dirawat, dan tidak menderita diare pada waktu masuk. Sedangkan kriteria eksklusi adalah pasien pulang paksa sebelum mendapat antibiotik 8 hari atau meninggal sebelum mendapat antibiotik 8 hari.

Analisis datadilakukan secara deskriptif dengan menghitung besaran frekuensi dan persentase, serta perhitungan analitik dilakukan dengan menggunakan uji statistik

\section{Hasil}

Selama periode penelitian didapatkan 38 pasien demam tifoid dan 12 pneumonia yang memenuhi syarat kriteria penelitian yang dirawat di Subbagian Infeksi dan Pulmonologi, Bagian Ilmu Kesehatan Anak 
FK-Unpad/RS Dr. Hasan Sadikin Bandung dan sebagai kontrol didapat 20 anak sehat.

\section{Karakteristik Subjek Penelitian}

Jenis kelamin, umur dan jenis antibiotik yang dipakai pada subjek penelitian tertera pada Tabel 1 .

Tabel 1. Karakteristik Subjek Penelitian

\begin{tabular}{lcc}
\hline Karakteristik & $\mathrm{n}$ & $\%$ \\
\hline 1. Jenis kelamin & & \\
- Laki-laki & 24 & 48,0 \\
- Perempuan & 26 & 52,0 \\
2. Umur (tahun) & & \\
- $1-4$ & 26 & 52,0 \\
- 5-9 & 13 & 26,0 \\
- 310 & 11 & 22,0 \\
3. Jenis antibiotik & & \\
- Ampisilin & 12 & 24,0 \\
- Kloramfenikol & 38 & 76,0 \\
\hline
\end{tabular}

Keterangan: $\mathrm{n}=$ jumlah subjek penelitian

Dari 50 pasien yang diteliti didapatkan $24(48,0 \%)$ anak laki-laki dan 26 (52,0\%) anak perempuan. Berdasarkan kelompok umur didapatkan 26 (52,0\%) anak berumur 1-4 tahun, $13(26,0 \%)$ anak berumur 5-9 tahun dan $11(22,0 \%)$ anak berumur 10 tahun atau lebih. Antibiotik kloramfenikol diberikan pada 38 (76,0\%) anak, sedangkan yang mendapat ampisilin sebanyak $12(24,0 \%)$ anak.

\section{Hasil Pemeriksaan Biakan Clostridium difficile Hari Pertama Perawatan}

Pada Tabel 2 terlihat bahwa biakan Clostridium difficile positif pada tinja anak pasien infeksi pada hari pertama perawatan $60,0 \%$. Hasil ini dibandingkan dengan kultur Clostridium difficile yang positif pada anak sehat, dengan tujuan untuk melihat apakah pemeriksaan kultur Clostridium difficile pada hari pertama perawatan (belum diberi antibiotik atau maksimum mendapat 3 hari antibiotik) sama dengan anak sehat. Kelompok kontrol terdiri dari anak sehat, 9 anak laki-laki dan 11 anak perempuan. Berdasarkan kelompok umur didapatkan 10 (50,0\%) anak berumur 1-4 tahun, 6 (30,0\%) anak berumur 5-9 tahun dan $4(20,0 \%)$ anak berumur 10 tahun atau lebih. Dari kelompok sehat ditemukan 8 anak dengan kultur Clostridium difficile positif $(40,0 \%)$ dan 12 anak dengan kultur negatif $(60,0 \%)$. Pada kelompok anak sehat tidak didapatkan toksin Clostridium difficile. Hal ini sesuai dengan laporan Triadafilopoulos dan La Mont (1991) bahwa pada anak sehat yang berumur lebih dari 1 tahun tidak didapatkan toksin Clostridium difficile, sedangkan pada anak sehat kurang dari 1 tahun didapatkan toksin Clostridium difficile sebesar 25-60\%.9 Perbandingan antara jumlah biakan Clostridium difficile pada anak sehat dengan pasien demam tifoid dan pneumonia pada hari pertama perawatan ditunjukkan pada Tabel 2 .

Tabel 2. Perbandingan Jumlah Biakan Clostridium difficile pada Anak Sehat dan Pasien Infeksi pada Hari Pertama Perawatan

\begin{tabular}{lllll}
\hline $\begin{array}{l}\text { Pemeriksaan } \\
\text { biakan }\end{array}$ & $\begin{array}{l}\text { Anak } \\
\text { sehat }\end{array}$ & & $\begin{array}{l}\text { Pasien } \\
\text { infeksi }\end{array}$ & \\
\hline & $\mathrm{n}$ & $\%$ & $\mathrm{n}$ & $\%$ \\
+ & 8 & 40,0 & 30 & 60,0 \\
- & 12 & 60,0 & 20 & 40,0 \\
Jumlah & 20 & 100,0 & 50 & 100,0 \\
\hline$x^{2}=1,56 ; \mathrm{p}=0,211$ & & &
\end{tabular}

Tabel 3. Jumlah koloni Clostridium difficile per gram tinja hari pertama perawatan

\begin{tabular}{llllll}
\hline Kelompok & $\mathrm{n}$ & Rerata & SB & Median & Rentang \\
\hline Sehat & 8 & 400,7 & 335,9 & 378 & $14-950$ \\
Pasien & 30 & 578,6 & 478,9 & 350 & $28-2.184$ \\
\hline
\end{tabular}

Keterangan: $\mathrm{SB}=$ Simpangan baku; $\mathrm{Z}_{\mathrm{M}-\mathrm{W}}=0,467 ; \mathrm{p}=0,461$

Dari Tabel 2 dan 3 tampak tidak ada perbedaan yang bermakna antara baik jumlah biakan positif maupun jumlah rata-rata koloni Clostridium difficile per gram tinja pada kelompok anak sehat dan pasien demam tifoid/pneumonia pada hari pertama perawatan.

Dari $8(40,0 \%)$ anak sehat dengan biakan Clostridium difficile positif, jumlah koloni bakteri tidak ada yang melebihi 103 koloni per gram tinja dengan rata-rata 400,7 koloni per gram tinja. 
Sari Pediatri, Vol. 6, No. 2, September 2004

\section{Jumlah Biakan dan Toksin Clostridium difficile pada Pasien Demam Tifoid dan Pneumonia (untuk Data Berpasangan)}

Tabel 5. Jumlah koloni Clostridium difficile per gram tinja pada pemeriksaan I dan II

\begin{tabular}{|c|c|c|c|c|c|}
\hline \multicolumn{6}{|l|}{$\begin{array}{l}\text { Pemeriksaan } \\
\text { Biakan }(+)\end{array}$} \\
\hline I & 27 & 496,7 & 497,2 & 280 & $28-2.184$ \\
\hline II & 27 & $1.739,1$ & $1.428,3$ & 1.288 & $252-4.928$ \\
\hline \multirow[t]{3}{*}{ Keterangan: } & $\mathrm{n}$ & \multicolumn{4}{|c|}{$\begin{aligned}= & \text { Jumlah hasil biakan Clostridium } \\
& \text { difficile yang positif }\end{aligned}$} \\
\hline & SB & \multicolumn{4}{|c|}{$=$ Simpangan baku } \\
\hline & $Z_{\text {Wilcoxon }}$ & \multicolumn{4}{|c|}{$=4,457 ; \mathrm{p}<0,001$} \\
\hline
\end{tabular}

Dari Tabel 5 terlihat bahwa terdapat perbedaan yang bermakna rata-rata jumlah koloni Clostridum difficile per gram tinja antara pemeriksaan I dengan pemeriksaan II, terjadi peningkatan jumlah koloni dari 496 menjadi 1.739 ( $\mathrm{p}<0,001)$.Hasil ini menunjukkan bahwa terjadi pertumbuhan atau peningkatan koloni Clostridium difficile secara bermakna pada anak yang menderita demam tifoid dan pneumonia setelah diberi antibiotik 8 hari.

Tabel 6. Pemeriksaan toksin Clostridium difficile pasien demam tifoid dan pneumonia pada pemeriksaan I dan II

\begin{tabular}{lcccc}
\hline & & \multicolumn{2}{c}{ Pemeriksaan I } & \multirow{2}{*}{ Jumlah } \\
\cline { 3 - 4 } & & + & - & \\
\hline \multirow{2}{*}{ Pemeriksaan } & + & 2 & 10 & 12 \\
& - & 0 & 38 & 38 \\
\hline \multirow{2}{*}{ Jumlah } & & 2 & 48 & 50 \\
\hline
\end{tabular}

$\mathrm{X}^{2} \mathrm{M-N}=\frac{[(\mathrm{b}-\mathrm{c})-1]^{2}}{\mathrm{~b}+\mathrm{c}}=\frac{[(10-0)-1]^{2}}{10}=8,1 \mathrm{p}<0,01$

Pada Tabel 6 terlihat bahwa pemeriksaan toksin Clostridium difficile pada hari pertama perawatan (maksimum mendapat 3 hari antibiotik) didapat pada 2 anak (4,0\%) dengan toksin positif dan 12 $(24,0 \%)$ anak toksin positif setelah pemberian antibiotik 8 hari. Terdapat perbedaan yang secara statistik bermakna antara jumlah pemeriksaan toksin Clostridium difficile positif pada pemeriksaan I dan II $(\mathrm{p}<0,01)$.
Tabel 7. Pemeriksaan Toksin Clostridium difficile dan Jumlah Koloni Clostridium difficile per Gram Tinja pada Pasien Demam Tifoid dan Pneumonia

\begin{tabular}{clllll}
\hline Pemeriksaan & & & & \\
Toksin & $n$ & Rerata & SB & Median & Rentang \\
\hline+ & 12 & $2.779,0$ & $1.373,0$ & $2.814,0$ & $1.120-4.928$ \\
- & 38 & 887,2 & 776,2 & 644,0 & $252-3.276$ \\
\hline
\end{tabular}

$\mathrm{Z}_{\mathrm{M}-\mathrm{W}}=3,741 ; \mathrm{p}=0,002$

Dari Tabel 7 terlihat bahwa pada pasien demam tifoid dan pneumonia terdapat perbedaan yang sangat bermakna rata-rata jumlah koloni per gram tinja antara pasien dengan toksin positif dan negatif $(p=0,002)$. Pada semua anak yang didapatkan toksin Clostridium difficile ternyata mempunyai jumlah koloni Clostridium difficile melebihi 103 koloni per gram tinja. Menurut Triadafilopoulos dan La Mont, pada pasien kolitis pseudomembran dengan toksin positif, lebih dari 95\% ditemukan jumlah koloni Clostridium difficile 103-107 koloni per gram tinja. ${ }^{?}$

\section{Hubungan Hasil Pemeriksaan Toksin Clostridium difficile Positif dan Diare}

Dari $12(24,0 \%)$ anak yang mempunyai hasil pemeriksaan toksin positif didapatkan 2 anak dengan gejala diare.

Pada penelitian ini ditemukan 2 gejala klinis yang mengarah pada diagnosis kolitis yaitu diare, sedangkan gejala klinis lain seperti kembung, mual, muntah, nyeri perut tidak ditemukan. Dapat disimpulkan bahwa diare yang terjadi kemungkinan salah satu gejala dari kolitis akibat pemakaian antibiotik.

Tabel 8. Hubungan pemeriksaan toksin Clostridium difficile positif dan diare

\begin{tabular}{|c|c|c|c|}
\hline & \multicolumn{2}{|c|}{ Diare } & \multirow{2}{*}{$\%(+)$} \\
\hline & + & - & \\
\hline Toksin (+) & 2 & 10 & 16,7 \\
\hline Toksin (-) & 0 & 38 & 0 \\
\hline
\end{tabular}

$\mathrm{p}=0,053$

Pada penelitian Bartlett dilaporkan bahwa pada kolitis pseudomembran yang terjadi akibat antibiotik didapatkan hasil pemeriksaan toksin positif sebanyak 95-100\%, dengan gejala diare tanpa kolitis pseudomembran $15-25 \%$ dan yang tanpa gejala hanya $2-8 \% .{ }^{10}$ 


\section{Diskusi}

Pada manusia sebagian besar bakteri yang membentuk flora normal adalah bakteri anaerob, yang paling sering ditemukan dalam saluran pencernaan terutama usus besar adalah Clostridium difficile. ${ }^{1}$ Pada orang dewasa didapatkan Clostridium difficile sekitar 3\%, pada bayi 20-50\% dan sangat tinggi pada neonatus 50-70\%.1,8 Sedangkan menurut Bartlett (1989) Clostridium difficile ditemukan 30-70\% pada neonatus ( $<1$ bulan), $30-70 \%$ pada bayi umur 1 bulan -1 tahun dan 3\% pada anak umur $>1$ tahun. ${ }^{10}$

Toksin Clostridium difficile ditemukan 5-63\% pada neonatus sehat, tidak didapatkan pada anak berumur lebih dari 1 tahun dewasa. ${ }^{8,10}$ Selain sebagai flora normal ternyata Clostridium difficile dapat sebagai penyebab kolitis. Bakteri ini pertama kali berhasil diisolasi pada tahun 1935 oleh Hall dan O'Toole. Mereka menamakan bakteri tersebut difficile oleh karena bakteri ini sangat sulit diisolasi. ${ }^{1}$ Umumnya penyakit yang disebabkan Clostridium difficile berhubungan dengan adanya pemberian antibiotik. Rolfe dkk dan Fekety dkk, menyatakan bahwa beberapa antibiotik yang sering berhubungan dengan timbulnya penyakit karena Clostridium difficile antara lain ampisilin, penisilin, klindamisin, kloramfenikol, tetrasiklin dan, sefaleksin. ${ }^{2,11}$ Sedangkan Allen dkk menyatakan bahwa hampir semua antibiotik, kecuali vankomisin, basitrasin dan metronidazol sering berhubungan dengan penyakit karena Clostridium difficile. ${ }^{1}$ Demikian juga Triadafilopoulos dan La Mont menyatakan bahwa hampir semua antibiotik dapat menyebabkan kolitis pseudomembran pada anak, tetapi yang paling sering adalah ampisilin. ${ }^{9}$ Bartlett melaporkan bahwa didapatkan hasil pemeriksaan toksin Clostridium difficile positif 15-25\% pada pasien diare yang berhubungan dengan pemberian antibiotik dan $2-8 \%$ pada pasien dengan pemberian antibitik yang tanpa disertai diare. ${ }^{9}$

Bagaimana hubungan antara lamanya pemberian, dosis dan rute pemberian antibiotik dengan terjadinya kolitis masih belum jelas.12 Menurut Banno dkk, timbulnya diare sebagai salah satu gejala dari kolitis dapat terjadi setelah 1 minggu pemberian antibiotik. Sedangkan Feigin dkk menyatakan bahwa timbulnya gejala dapat terjadi selama pemberian antibiotik (hari ke 4-8) atau terjadi sangat lambat, yaitu sampai 21 hari setelah antibiotik dihentikan. ${ }^{8,13}$

Clostridium difficille dalam bermultiplikasi dan berproliferasi membentuk toksin. Adanya toksin dalam tinja pasien kolitis yang disebabkan oleh Clostridium difficile pertama kali dilaporkan oleh Larson dkk, kemudian George dkk berhasil mengisolasi Clostridium difficile dari tinja pasien kolitis akibat pemakaian klindamisin. ${ }^{11,14}$ Selain itu juga dia berpendapat bahwa toksin yang dihasilkan merupakan satu-satunya penyebab terjadinya kolitis.

Pada penelitian ini terlihat terjadi peningkatan populasi Clostridium difficile setelah pemberian antibiotik 8 hari, yaitu pada hari ke-1 nilai median adalah 280 meningkat menjadi 1288 dan terbentuknya toksin Clostridium difficile pada 12 dari 50 pasien serta adanya hubungan antara adanya toksin Clostridium difficile dengan gejala klinis diare yaitu 2 dari 12 yang toksin positif (merupakan gejala tersering dari kolitis).

\section{Daftar Pustaka}

1. Allen SD, Ellen JB. Clostridium. Dalam: Ballows A, William J, Hausler JR, Kenneth LH, Henry DI, Shadoy $\mathrm{HJ}$, penyunting. Manual of clinical microbiology. Edisi ke-5. Washington DC: American Society for Microbiology; 1991. h. 505-21.

2. Rolfe RD, Finegold SM. Purification and characterization of Clostridium difficile toxin. Infect Immun 1979;25:191-202.

3. Schuller I, Saha V, Lin Linm Kingston J, Eden T, Tabaqchali. Investigation and management of Clostridium difficile colonization in a paediatric oncology unit. Arch Dis Child 1995;72:219-22.

4. Supardi I. Pola kepekaan kuman isolat dari bahan klinik di Bandung terhadap berbagai jenis antibiotik. MKB 1988;XXI:41-8.

5. Rosmajudi O, Kartasasmita CB. Pneumonia. Dalam: Garna H, Widjaya J, Rustama DS, Rahman O, Sjahrodji AM, penyunting. Pedoman terapi ilmu kesehatan anak. Edisi ke-1. Bandung: Bina Budhaya; 1993. h. 179-83.

6. Azhali MS, Garna H, Chairulfatah A. Penyakit infeksi tropis. Dalam: Garna H, Widjaya J, Rustama DS, Rahman O, Sjahrodji AM, penyunting. Pedoman terapi ilmu kesehatan anak. Edisi ke-1. Bandung: Bina Budhaya; 1993. h. 106-7.

7. Jawetz EJL, Melnick, Adelberg EA. Spore-forming gram positive bacilli: bacilllus \& clostridium spesies. Dalam: Jawetz EJL, penyunting. Review of medical microbiology. Edisi ke-16. Los Altos: Lange Medical Publication; 1984. h. 180-7. 
Sari Pediatri, Vol. 6, No. 2, September 2004

8. Feigin RD, Finta KM. Antibiotic associated colitis, pseudomembranous colitis. Dalam: Behrman RE, Kliegman RM, Nelson WF, Vaughan III VC, penyunting. Nelson textbook of pediatrics. Edisi ke-14. Philadelphia: WB Saunders Co; 1992. h. 750-2.

9. Triadafilopoulos G, La Mont JT. Pseudomembranous colitis. Dalam: Walker WA, Durie PR, Hamilton JR, Walker-Smith JA, Watkins JB, penyunting. Pediatric gastrointestinal disease patophysiology, diagnosis, management, vol 1. Philadelphia: BC Decker Inc; 1991. h. 619-29.

10. Bartlett JG. Gastrointestinal disease, patophysiology diagnosis management. Edisi ke-4. Philadelphia: WB Saunders Co; 1989.

11. Fekety R, Kim KH, Bats DH, Browne MA, Silva J Jr, Toshival R. Studies on the epidemiology of antibioticasociated Clostridium difficile colitis. Am J Clin Nutr 1980;33:2527-32.

12. Prince AS, Neu HC. Antibiotic-associated pseudomembranous colitis in children. Ped Clin North Am 1979;26:261-8.

13. Banno Y, Kobayashi T, Kono, Watanabe K, Ueno K, Nozawa Y. Biochemical characterization and biologic action of two toxins (D-1 and D-2) from Clostridium difficile. Rev Infect Dis 1984;6:S11-9.

14. George WL, Goldstein EJC, Finegold SM. Aetiology of antimicrobial agent-associated colitis. Lancet 1978;15:802-3. 